\title{
The Influence of Keratometry on Visual and Refractive Outcomes after Myopic LASER in Situ Keratomileusis
}

\author{
Sara Frazão, Pedro Rodrigues, Samuel Alves, Ana Maria Carvalho, \\ José Maia Sêco, Hugo Nogueira
}

Instituto de Oftalmologia Dr. Gama Pinto, Lisbon, Portugal

Email: saraifrazao@gmail.com

How to cite this paper: Frazão, S., Rodrigues, P., Alves, S., Carvalho, A.M., Sêco, J.M. and Nogueira, H. (2018) The Influence of Keratometry on Visual and Refractive Outcomes after Myopic LASER in Situ Keratomileusis. Open Journal of Ophthalmology, 8, 84-90.

https://doi.org/10.4236/ojoph.2018.82012

Received: March 27, 2018

Accepted: May 8, 2018

Published: May 11, 2018

Copyright $\odot 2018$ by authors and Scientific Research Publishing Inc. This work is licensed under the Creative Commons Attribution International License (CC BY 4.0).

http://creativecommons.org/licenses/by/4.0/

\begin{abstract}
To evaluate the effect of preoperative keratometry on visual and refractive outcomes after Myopic LASER in Situ Keratomileusis (LASIK) in eyes with preoperative spherical equivalent (SE) of $-6.00 \mathrm{D}$ or less. Material and Methods: A retrospective study enrolling clinical records of 482 eyes of 275 patients with myopia who underwent LASIK between 2009 and 2016. Subjects were grouped according to the degree of preoperative mean keratometry $(\mathrm{Km})$, into three groups: Group 1 (Flat Cornea): $\mathrm{Km} \leq 42.00$ diopters (D); Group 2: $42.00<\mathrm{Km}>46.00 \mathrm{D}$; Group 3 (Steep Cornea): $\mathrm{Km} \geq 46.00 \mathrm{D}$. To evaluate the prognostic impact of keratometry in Myopic LASIK, we considered the results measured at 6 months postoperatively, including uncorrected distance visual acuity (UDVA), postoperative sphere, cylinder, SE and its variation. Results: The mean preoperative SE was $-3.91 \pm 1.54 \mathrm{D}$, ranging between -0.88 and $-6.00 \mathrm{D}$. The percentage of eyes achieving a postoperative SE of $\pm 0.50 \mathrm{D}$ was $39.5 \%, 31.8 \%$ and $26 \%$ in groups 1,2 and 3 respectively. Moreover, in group 3,14.3\% of the eyes had a residual SE of $-2.00 \mathrm{D}$ or greater, contrasting with the groups 1 and 2 with only $6 \%-7 \%$. These results were found to be statistically significant. Concerning UDVA, eyes achieving 20/25 or more were $81.5 \%, 81.8 \%$ and $71.5 \%$, and $20 / 50$ or less were $6.7 \%, 6.2 \%$ and $11.7 \%$ in groups 1, 2 and 3 respectively. Conclusions: Myopic eyes with steeper corneas seem to have greater tendency to undercorrection, also presenting worse visual outcomes.
\end{abstract}

\section{Keywords}

Myopia, Astigmatism, LASER in Situ Keratomileusis, Keratometry, Spherical Equivalent, Flat Cornea, Steep Cornea 


\section{Introduction}

Laser in situ keratomileuis (LASIK) is, nowadays, the most commonly performed keratorefractive surgery, with well-established surgical indications, with numerous studies validating its long-term efficacy and safety [1]. Many prognostic factors have been investigated concerning their contribution to the predictability of this procedure.

LASIK is based on the modification of corneal curvature, inducing biomechanical changes with the purpose of altering refractive power [2]. Myopia and myopic astigmatism are corrected by the flattening of its central anterior surface, so that the increase of corneal radius will lower dioptric power with the objective of emmetropization [3]. For this reason, keratometry is a potential prognostic factor, which could in part explain cases of residual postoperative refractive error or unsatisfactory visual outcome. The specific influence of this prognostic factor is contradictory in the literature [4] [5]. Studies reported a trend toward undercorrection in flat corneas in eyes with high myopia, whereas, studies analyzing moderate myopia reported better refractive and visual outcomes in such corneas with lower mean keratometry.

The purpose of our study is to evaluate the effect of preoperative mean keratometry on refractive and visual outcomes of LASIK in myopic eyes with preoperative spherical equivalent (SE) of -6.00 or less.

\section{Subjects and Methods}

The clinical records of patients who underwent LASIK between 2009 and 2016 in Instituto de Oftalmologia Dr. Gama Pinto (IOGP) were retrospectively analyzed. As inclusion criteria, we considered myopic eyes with a preoperative spherical equivalent of $-6.00 \mathrm{D}$ or less, without prior history of ocular procedures or other known ocular pathology, including keratoconus or high-order aberrations, with a minimum follow-up period of 6 months postoperatively. Due to the retrospective nature of this study, the sample size was limited to the number of subjects respecting inclusion criteria.

LASIK was performed with the Lasersight Laserscan Lsx Excimer Laser System (Lasersight Technologies, Inc), using standard protocol, by four different refractive surgeons at IOGP. The preoperative keratometry and pachymetry were considered to plan the surgery. The minimum residual stromal bed was planned to be greater than $250 \mu \mathrm{m}$ to avoid excessive corneal thinning and possible post-LASIK ectasia. Emmetropia was the final goal in all cases. The superior lamellar flaps were created with the microkeratome MORIA One Use-Plus SBK, creating a $6.5 \mathrm{~mm}$ optical zone with $8 \mathrm{~mm}$ of blend zone, centered with the center of the pupil. Following ablation, the flap was replaced. Postoperative evaluation and measurements included in this study took place at 6 months post-LASIK.

Subjects were grouped according to the degree of preoperative mean keratometry $(\mathrm{Km})$, into three groups [3]: Group 1 included eyes with a flat cornea, 
with $\mathrm{Km}$ of 42.00 diopters (D) or less; Group 2, included eyes with $\mathrm{Km}$ ranging from $42.00 \mathrm{D}$ to $46.00 \mathrm{D}$; Group 3 included eyes with steep corneas, with $\mathrm{Km}$ of $46.00 \mathrm{D}$ or higher. In order to evaluate the prognostic impact of keratometry in myopic LASIK, we considered the results measured at 6 months postoperatively, including uncorrected distance visual acuity in ETDRS grading system (UDVA), sphere, cylinder, SE and its variation. Corneal keratometry and refractive values of sphere and cylinder were measured by a trained technician with an auto-refractometer and keratometer. The variation in keratometry $(\Delta \mathrm{K})$ and spherical equivalent $(\Delta \mathrm{SE})$ were calculated subtracting the postoperative value to the preoperative measurement.

The statistical analysis was performed with IBM $^{\oplus}$ SPSS ${ }^{\oplus}$ Statistics version 23 software. Descriptive statistics were performed, including means, standard deviation $(\mathrm{SD})$, minimum $(\mathrm{min})$ and maximum $(\max )$ and percentage of qualitative variables. The Kruskal-Wallis $\mathrm{H}$ test was performed, a non-parametric test for independent variables, with a Mann-Whitney $U$ post-hoc test, to compare the keratometry groups (independent factor), with the corresponding SE and UCVA as dependent factors. The results were considered statistically significant if $\mathrm{p}<$ 0.05 . The Spearman's correlation test was run to analyze correlation between variables.

\section{Results}

A total of 482 eyes of 275 patients were enrolled in this study, having met all inclusion criteria. The demographic data and preoperative characteristics are summarized in Table 1.

In our study, the mean age was of $32 \pm 6.3$ years old, ranging from 20 to 53 years old. The average of SE was $-3.90 \pm 1.54 \mathrm{D}$, ranging from -6.00 to $-0.88 \mathrm{D}$. The mean pachymetry was $549.5 \pm 27.9 \mu \mathrm{m}$ and mean $\mathrm{Km}$ was $43.64 \pm 1.40 \mathrm{D}$, ranging from 40.38 to $48.13 \mathrm{D}$.

The preoperative characteristics of each $\mathrm{Km}$ group are organized in Table 2. Group 1 included a total of 116 eyes; group 2 included 283 eyes and group 3 included 77 eyes. All three groups had a mean preoperative SE ranging from 3.50 to 4.00 negative diopters. The average preoperative $\mathrm{Km}$ was of $40.80 \pm 0.47 \mathrm{D}$ in group 1, ranging between 40.38 and $42.00 \mathrm{D}$, representing flat corneas; $43.83 \pm$ $0.69 \mathrm{D}$ in group 2, ranging between 42.25 and $45.75 \mathrm{D}$; and $46.79 \pm 0.63 \mathrm{D}$ in group 3, ranging between 46.00 and $48.13 \mathrm{D}$, representing steep corneas. The average pachymetry in group 1 was of $552.43 \pm 32.27 \mu \mathrm{m}, 547.29 \pm 26.22 \mu \mathrm{m}$ in group 2 and $553.5 \pm 26.5 \mu \mathrm{m}$ in group 3 .

The mean ablation depth in group 1 was $57.60 \pm 19.55 \mu \mathrm{m}$, contrasting with $66.35 \pm 19.0 \mu \mathrm{m}$ in group 3 which was considerably higher. This difference might be due to the slightly lower preoperative sphere and SE values in group 1, comparing to the other groups.

A significant statistical moderate correlation was found between the variation of preoperative and postoperative $\mathrm{Km}(\Delta \mathrm{Km})$ and the variation of SE $(\Delta \mathrm{SE})$ after LASIK $(\mathrm{R}=0.51 \mathrm{p}<0.01)$ 
Table 1. Global demographic characteristics $(\mathrm{N}=482$ eyes $)$.

\begin{tabular}{|c|c|c|}
\hline \multicolumn{3}{|c|}{ Global Demographic Characteristics } \\
\hline M:F & & \\
\hline Age & $32.9 \pm 6.3$ & (20 to 53$)$ \\
\hline Spherical Equivalent (D) & $-3.90 \pm 1.54$ & $(-6.00$ to -0.88$)$ \\
\hline Sphere (D) & $-3.30 \pm 1.66$ & $(-6.00$ to 0.00$)$ \\
\hline Cylinder (D) & $-1.20 \pm 1.13$ & $(-5.50$ to 0.00$)$ \\
\hline $\mathrm{K} 1(\mathrm{D})$ & $42.97 \pm 1.47$ & (39.50 to 47.50$)$ \\
\hline K2 (D) & $44.34 \pm 1.42$ & (40.50 to 49.00 ) \\
\hline $\mathrm{Km}(\mathrm{D})$ & $43.64 \pm 1.40$ & (40.38 to 48.13 ) \\
\hline Pachymetry $(\mu \mathrm{m})$ & $549.5 \pm 27.9$ & (480 to 633$)$ \\
\hline Ablation Depth $(\mu \mathrm{m})$ & $63.16 \pm 19.6$ & (23 to 113 ) \\
\hline
\end{tabular}

Table 2. Demographic characteristics in preoperative period divided by groups of mean keratometry (mean \pm standard deviation (minimum to maximum)).

\begin{tabular}{|c|c|c|c|c|c|c|}
\hline \multirow[b]{2}{*}{ Parameter } & \multicolumn{2}{|c|}{$\begin{array}{c}\text { Group } 1 \text { - Flat Cornea } \\
\mathrm{Km} \leq 42.00 \mathrm{D} \\
(\mathrm{N}: 116)\end{array}$} & \multicolumn{2}{|c|}{$\begin{array}{c}\frac{\text { Group 2 }}{42.00 \mathrm{D}}<\mathrm{Km}>46.00 \mathrm{D} \\
(\mathrm{N}: 283)\end{array}$} & \multicolumn{2}{|c|}{$\begin{array}{c}\text { Group } 3 \text { - Steep Cornea } \\
\mathrm{Km} \geq 46.00 \mathrm{D} \\
(\mathrm{N}: 77)\end{array}$} \\
\hline & Mean \pm SD & Min to $\max$ & Mean \pm SD & Min to $\max$ & Mean \pm SD & Min to $\max$ \\
\hline Spherical Equivalent (D) & $-3.47 \pm 1.54$ & $(-6.00$ to -1.00$)$ & $-4.06 \pm 1.55$ & $(-6.00$ to -1.00$)$ & $-3.99 \pm 1.38$ & $(-6.00$ to -1.75$)$ \\
\hline Sphere (D) & $-2.71 \pm 1.67$ & $(-6.00$ to 0.00$)$ & $-3.53 \pm 1.60$ & $(-6.00$ to 0.00$)$ & $-3.33 \pm 1.61$ & $(-6.00$ to -0.50$)$ \\
\hline Cylinder (D) & $-1.51 \pm 1.29$ & $(-5.00$ to 0.00$)$ & $-1.06 \pm 1.01$ & $(-5.50$ to 0.00$)$ & $-1.25 \pm 1.21$ & $(-4.50$ to 0.00$)$ \\
\hline K1 (D) & $40.15 \pm 0.75$ & (39.50 to 42.00$)$ & $43.20 \pm 0.84$ & (40.75 to 45.00$)$ & $44.92 \pm 0.99$ & (42.50 to 47.50$)$ \\
\hline K2 (D) & $42.67 \pm 0.77$ & (40.50 to 45.00$)$ & $44.45 \pm 0.76$ & (42.75 to 46.50$)$ & $47.91 \pm 0.71$ & (46.00 to 49.00$)$ \\
\hline Mean K (D) & $40.80 \pm 0.47$ & (40.38 to 42.00$)$ & $43.83 \pm 0.69$ & (42.25 to 45.75$)$ & $46.79 \pm 0.63$ & (46.00 to 48.13 ) \\
\hline Pachymetry $(\mu \mathrm{m})$ & $552.43 \pm 32.27$ & (480 to 633$)$ & $547.29 \pm 26.22$ & (492 to 622 ) & $553.5 \pm 26.5$ & (505 to 624$)$ \\
\hline Ablation Depth $(\mu \mathrm{m})$ & $57.60 \pm 19.55$ & (23 to 112 ) & $64.61 \pm 19.48$ & (23 to 113 ) & $66.35 \pm 19.0$ & (23 to 101 ) \\
\hline
\end{tabular}

The refractive and keratometric outcomes at 6 months postoperatively are summarized in Table 3, according to $\mathrm{Km}$ group. The mean postoperative $\mathrm{Km}$ was of $39.99 \pm 1.25 \mathrm{D}$ in group $1,41.40 \pm 1.54 \mathrm{D}$ in group 2 and $43.16 \pm 1.46 \mathrm{D}$ in group 3. Concerning keratometry variation and SE variation, group 3, representing steep corneas, seemed to have a greater difference between preoperative and postoperative values, with a $\Delta \mathrm{SE}$ of $2.98 \pm 1.39 \mathrm{D}$ and a $\Delta \mathrm{Km}$ of 2.63 $\pm 1.34 \mathrm{D}$, therefore a greater surgical effect, when compared with group 1, representing flat corneas with a $\Delta \mathrm{SE}$ of $2.66 \pm 1.43 \mathrm{D}$ and a $\Delta \mathrm{Km}$ of $1.83 \pm 1.20 \mathrm{D}$. This difference was statistically significant $(\mathrm{p}<0.008)$.

However, analyzing the distribution of refractive results in each $\mathrm{Km}$ group (Figure 1), we found that group 3, the steep cornea group had an overall tendency for undercorrection when compared to other groups, with $14 \%$ of the eyes with a residual SE of $-2.00 \mathrm{D}$ or more, contrasting with group 1 and 2 where 
Table 3. Results and variable variations at 6 months postoperatively (mean \pm standard deviation).

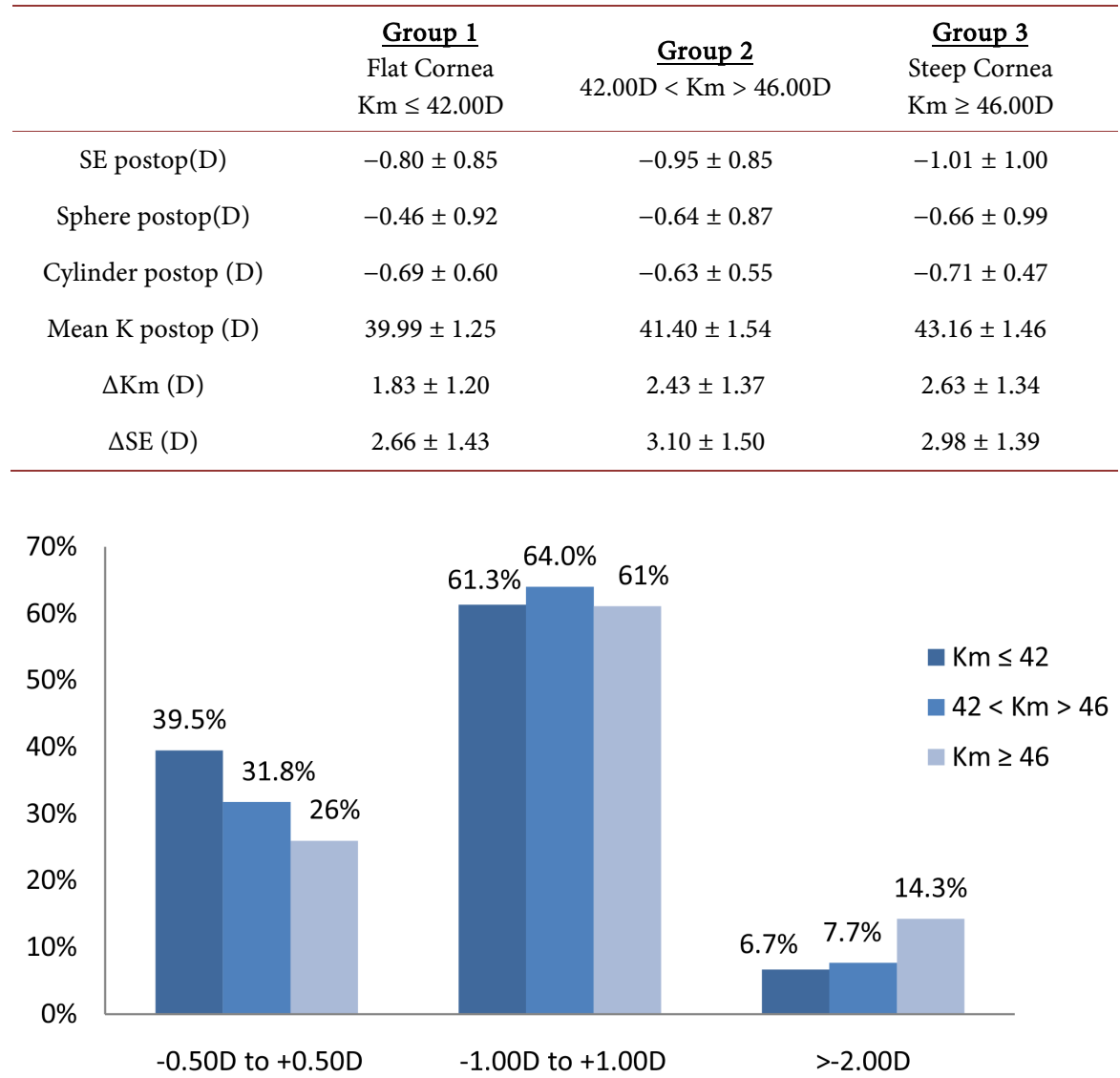

Figure 1. Distribution of postoperative SE refraction by Km group.

only $6.7 \%$ and $7.7 \%$ of eyes respectively, were left with this degree of undercorrection. The percentage of eyes achieving a postoperative SE between -0.50 and $+0.50 \mathrm{D}$, therefore achieving surgical success, was of $39.5 \%, 31.8 \%$ and $26 \%$ in groups 1, 2 and 3 respectively.

Considering visual outcomes, steep corneas also seemed to have worse UDVA comparing to eyes in the other groups. Figure 2 shows the cumulative UDVA among the keratometry groups, where slightly more than $81 \%$ of subjects on both group 1 and 2 achieved 20/25 vision or more, whereas only $71.5 \%$ of subjects in group 3 achieved the same vision. Additionally, almost $11.7 \%$ of eyes in group 3 were left with $20 / 50$ vision or worse, contrasting with $6.7 \%$ and $6.2 \%$ in groups 1 and 2 respectively.

\section{Discussion}

The influence of keratometry on refractive outcomes of myopic LASIK has already been debated in various studies, although with contradictory results. Rao et al. [6] reported a trend toward undercorrection in flat corneas in eyes with preoperative SE of -10.00 to $-11.99 \mathrm{D}$. Perez-Santonja et al. [7] reported the same results in eyes with preoperative SE of -8.00 to $-20.00 \mathrm{D}$. Mostafa et al. [5] also 


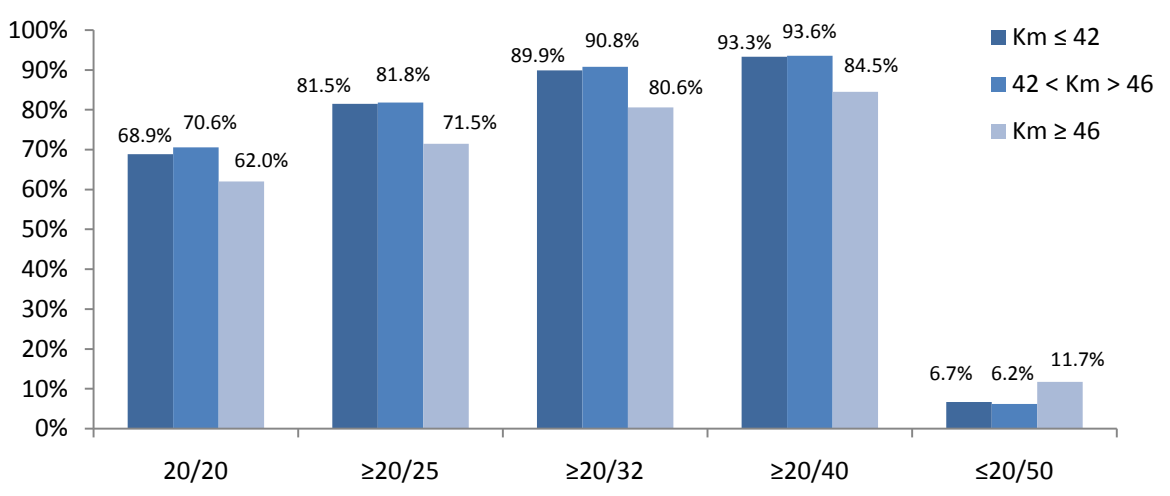

Figure 2. Distribution of Cumulative UDVA among keratometry groups.

reported tendency for undercorrection in flat corneas in myopic eyes with preoperative SE ranging from -6.00 to $-12.00 \mathrm{D}$. Contrasting with these studies, Christiansen et al. [4] studied moderate myopia, with preoperative SE ranging from -2.00 to $-5.99 \mathrm{D}$, reporting better refractive and visual outcomes in flat corneas. The difference between these contrasting results lies in the different grades of myopia analyzed in each study. Studies reporting tendency for undercorrection in flat corneas analyzed subjects with high myopia, who were originally excluded from our study due to the fact that eyes with high myopia do not have surgical indication for LASIK in our institution.

Our results seem to be concordant with Christiansen et al. [4] findings concerning refractive and visual outcomes after LASIK, with steeper corneas showing a greater tendency toward refractive undercorrection and worse visual outcomes. We found a significant correlation between the variation of keratometry and spherical equivalent after LASIK in the evaluated population.

In our study, all three groups were homogeneous concerning preoperative SE and pachymetry. The mean ablation depth performed was greater in steeper corneas comparing to the other groups, showing greater variation of $\mathrm{Km}$ after LASIK, with an apparent greater surgical effect. However, although steep corneas suffered a greater corneal applanation, this was not reflected on SE variation in the same magnitude. Despite the greater ablation depth and surgical effect in steeper corneas, these showed a greater tendency for undercorrection concerning SE and worse visual outcomes comparing to other degrees of preoperative keratometry. Christiansen et al. proposes more aggressive laser ablation in eyes with $\mathrm{Km} \geq 46.00 \mathrm{D}$.

One of our study's limitations is its retrospective nature, with a short follow-up period especially due to disparity in clinical records. It would be interesting to project a prospective longitudinal study, with a larger population, dividing the sample per myopia grades, so as to categorize the influence of keratometry in different grades of preoperative myopia. This would certainly be helpful in clinical practice, to optimize the procedure and maximize the success of this refractive surgery.

In conclusion, myopic eyes with steeper corneas seem to have greater tendency to undercorrection, also presenting worse visual outcomes. 


\section{References}

[1] Schallhorn, S.C., et al. (2015) Effect of Postoperative Keratometry on Quality of Vision in the Postoperative Period after Myopic Wavefront-Guided Laser in Situ Keratomileusis. Journal of Cataract \& Refractive Surgery, 41, 2715-2723. https://doi.org/10.1016/j.jcrs.2015.06.034

[2] Seven, I., et al. (2016) Comparison of Patient-Specific Computational Modeling Predictions and Clinical Outcomes of LASIK for Myopia. Investigative Ophthalmology \& Visual Science, 57, 6287-6297. https://doi.org/10.1167/iovs.16-19948

[3] Kim, G., et al. (2014) Change in Keratometry after Myopic Laser in Situ Keratomileusis and Photorefractive Keratectomy. Journal of Cataract \& Refractive Surgery, 40, 564-574. https://doi.org/10.1016/j.jcrs.2013.09.016

[4] Christiansen, S., et al. (2012) The Effect of Preoperative Keratometry on Visual Outcomes after Moderate Myopic LASIK. Clinical Ophthalmology, 6, 459-464.

[5] Mostafa, E.M., et al. (2015) Effect of Flat Cornea on Visual Outcome after LASIK. Journal of Ophthalmology, 2015, 7. https://doi.org/10.1155/2015/794854

[6] Rao, S.K., et al. (2001) Effect of Preoperative Keratometry on Refractive Outcomes after LASIK. Journal of Cataract \& Refractive Surgery, 27, 297-302. https://doi.org/10.1016/S0886-3350(00)00746-X

[7] Perez-Santonja, J.J., et al. (1997) Laser in Situ Keratomileusis to Correct High Myopia. Journal of Cataract \& Refractive Surgery, 23, 372-385.

https://doi.org/10.1016/S0886-3350(97)80182-4 